\title{
The use of microchannels for separation and preconcentration: comparison between three-dimensional and planar configurations
}

\author{
Uso de microcanais para separação e pré-concentração: comparação \\ entre configurações tridimensionais e planares \\ Lilian Silva ${ }^{1}$, Roberto Lima ${ }^{1}$, Eliphas Simões ${ }^{1}$, Maria Lúcia Silva $^{1,2}$
}

\begin{abstract}
Simulation and experimental measurements were used aiming at better understanding flow behavior in planar and three-dimensional microchannels used for separation or preconcentration. Two different microchannels configurations were designed, manufactured in acrylic and the surface was modified to adsorb volatile organic compounds (VOCs). Both channels configuration are $73 \mathrm{~cm}$ long, $100 \mu \mathrm{m}$ wide and $40 \mu \mathrm{m}$ deep. Simulation was carried out in COMSOL (FEMLAB) $3.2^{\circledR}$ and COSMOS flow 5. $0^{\circledR}$ programs, tracer visualization and quartz crystal microbalance data were evaluated according to chromatographic concepts. Due to the higher axial velocity, planar microchannels are more adequate for preconcentration whereas three-dimensional ones show a good performance in the separation process.
\end{abstract}

Keywords: Microchannels; Planar, Three-dimensional, Preconcentration.

\section{Resumo}

Foram usadas simulações computacionais e medidas experimentais com o objetivo de compreender o comportamento de fluidos em microcanais tridimensionais e planares que foram testados na função de separação ou pré-concentração. Duas configurações diferentes foram projetadas, construídas em acrílico e tiveram sua superfície modificada para adsorver compostos orgânicos voláteis (COVs). Ambas as configurações de canal apresentam $73 \mathrm{~cm}$ de comprimento, $100 \mu \mathrm{m}$ de largura e $40 \mu \mathrm{m}$ de profundidade. A simulação utilizou os softwares COMSOL (FEMLAB) $3.2^{\circledR}$ e COSMOS flow 5.0 ${ }^{\circledR}$ enquanto a experimentação usou visualização com traçadores e medidas com microbalança de quartzo, com os dados sendo analisados com base em conceitos cromatográficos. Devido à maior velocidade axial observada nos microcanais planares, este são mais adequados à pré-concentração enquanto microcanais tridimensionais apresentam boa performance no processo de separação.

Palavras-chave: Microcanais; Planar, Tri-dimensional, Pré-concentração. 


\section{Introdução}

One of the most common consequences of MEMS (Microelectromechanical Systems) development is the use of microchannels for several distinct purposes, especially in Chemistry and Chemical Engineering fields ${ }^{(1-5)}$. Microchannels can easily be used for different fluids transporting, mixing and reacting, i.e., they serve several different Chemical Engineering unit operations. Moreover, they are also common to separate components in a complex mixture, or to execute analytical processes in continuous flow, i.e., important goals for Analytical Chemistry ${ }^{(6-8)}$, as well. Therefore, microchannels perform tasks from relatively simple devices to completely automatic equipment; thus, the production and simulation of microchannels present interesting challenges to be met.

The high surface/volume ratio is a topmost advantage concerning microchannels ${ }^{(9)}$ and leads to several uses in chemical analysis, such as sample pretreatment; therefore, two important functions carried out inside microchannels are preconcentration and separation of components in a complex mixture. Macroscopic devices that perform such tasks are usually manufactured using capillary tubes. However, the scale up of such structures presents some hindrances; due to the use of microelectronics technology for production of MEMS devices, microchannels are normally obtained in a planar shape ${ }^{(10)}$. Nonetheless, Sandia Lab. ${ }^{(11,12)}$, among several others, proposed a layout that suspended the adsorbent inside the device ${ }^{(13)}$, or even the column ${ }^{(14)}$, which is a good approximation of three-dimensional devices.

Separation of components is another important use for microchannels that normally rely on the manufacturing of a planar structure, normally microchromatographic columns. These columns are intended to portable gas chromatograph systems, the development of which in the past four decades led to several innovations, not only in columns, but also in detectors; however, some difficulties still remain, specially regarding the integration of each part to the whole equipment ${ }^{(15,16)}$.

The column is the core of a chromatograph and its miniaturization produced an enormous variety of layouts, but the use of a planar spiral ${ }^{(12,17-19)}$ is not uncommon, as explained later, or a serpentine shape ${ }^{(20)}$. However, three-dimensional microchannels are rarely considered for such equipment and the three-dimensionality concept is usually more referred to high aspect ratio and sudden velocity variations, but reproduced in a flat surface ${ }^{(14,19)}$, than in production processes based on two or more layers ${ }^{(21)}$. In fact, device manufacturing with more than one layer is linked to fluid mixing ${ }^{(22)}$, mainly due to the formation of advection zones originated in that approach ${ }^{(23)}$, but some artifices are attempted in order to obtain similar effects using 2D channels ${ }^{(24)}$. Nonetheless, spiral and helical tubes were already extensively simulated and, as stated in a recent review ${ }^{(25)}$, are adequate as passive mixers and heat transfers. In these channels, centrifugal forces, pressure gradients and no-slip wall condition are critical parameters, which suggest that helical structures present some advantages over planar configuration. Moreover, curved flow can present secondary flow that favors the occurrence of a turbulent regime and Dean number correlates such flow variations and tube curvature. However, a general equation correlating Dean number and curve geometry has not been found yet and some empirical constants are usually added.

In our former works, planar and three-dimensional channels were used as preconcentrators ${ }^{(26-28)}$ and/or microchromatographic columns ${ }^{(29,30)}$. The planar channel is a spiral quite similar to those used in chromatographic columns; nonetheless retention occurred due to capillary effects because the flow was not completely laminar, or not ideal Hagen-Poiseuille flow, and some constrictions favored interactions with the wall ${ }^{(27)}$. A similar result was obtained with a planar spiral channel for cell separation; in this case, the cell must find the channel wall that was modified with antibodies ${ }^{(31)}$. This channel and the preconcentrator have compatible depths, $50 \mu \mathrm{m}$ and $40 \mu \mathrm{m}$ dimension respectively, but other dimensions are different: width of $310 \mu \mathrm{m}$ and $100 \mu \mathrm{m}$, length varying between $4 \mathrm{~cm}, 20 \mathrm{~cm}$ and $73 \mathrm{~cm}$, respectively. The three-dimensional channels were machined with the same dimensions used on planar structures, but utilized a tubular substrate, i.e. it is helical but manufactured without using of planar or multi layer processes approaches. This channel showed a laminar flow and easiness of sample removal even at high temperatures ${ }^{(32)}$. Since a long time ago, based on experimental results, curved tubes are considered ideal for chromatographic purposes with important axial effects appearing only with very low linear velocities ${ }^{(33,34)}$. Nonetheless, helical tubes were used as mixers and the mixing mechanisms involve molecular diffusion and secondary flow, which is usually characterized by Reynolds Numbers. Therefore, at low Reynolds numbers $(<10)$, i. e. ideal laminar flow, the secondary flow presents low intensity. In Reynolds number range of 10 to 100 , pseudo laminar flow, they are 
efficient static mixers, with a stronger secondary flow at a lower curvature ratio ${ }^{(35)}$.

Preconcentrators may use turbulent flow, Reynolds Numbers above 2,300, and secondary phenomena, such as capillary effects, to improve retention; on the other hand, in chromatographic columns, turbulence might increase eddy diffusion and hinder separation. Therefore, the conditions under which 2D or 3D channels can perform such tasks are quite dependent on velocity profile and surface interactions. Thus, this work aimed at better understanding, not only by simulation but also by comparison with experimental results, flow behavior in some planar and three-dimensional microchannels.

\section{Experimental}

Concepts involved

Tracers - the injection of products in a flow in order to understand their behavior is not uncommon. Bedmar states that these products, named tracers ${ }^{(36)}$, present one distinguished characteristic if compared to the flow but they must also have the same hydrodynamic behavior of the main product in the flow. Furthermore, tracers cannot be lost in the path between injection and measurement and must be easily and efficiently detected in the flow by the use of simple instruments and techniques. Tracers have been used for flow determination in microstructures, especially for understanding the mixing properties of the devices. Mengeaud ${ }^{(37)}$ used a fluorescent compound and Xia employed ${ }^{(38)}$ a high viscous glycerol solution and two different dyes to evaluate mixing properties of a microstructure in high and in low Reynolds number conditions, respectively. Kang simulates particles traveling in a channel and compared these simulated results with micrographs of a fluorescent compound ${ }^{(39)}$.

Chromatographic definitions - Although a chromatographic column performance depends on several physical and operational parameters, some meaningful information can be obtained by analyzing the time required for an analyte to be removed from the column and the concentration profile of that analyte in the column outlet. The time for analyte removal (retention time) is mainly correlated to adsorption in the stationary phase and velocity in the mobile phase. The concentration profile is due to many parameters and is usually described by van Deemter
Equation $^{(1)}$. Therefore, each parameter in Eq. 1 explains some factors that influence peak broadening. The main premises that lead to a sum in Eq 1 is that these different processes are independent of one another and each of them generates a Gaussian probability distribution.

$$
H=A+\frac{B}{u}+C u
$$

where, $H$ is the height equivalent to a theoretical plate (i.e., the space required to achieve equilibrium between the mobile and stationary phases); $u$ is the linear velocity of the mobile phase; $A / B / C$ are constants, each related with the column parameters as follows: $A$ - the column geometry; $B$ - longitudinal diffusion in the mobile phase, $C$ - resistance to mass-transfer processes.

Constant $A$ accounts for the effects of "eddy" diffusion and other factors in the column. The longitudinal diffusion is proportional to the resident time of the analyte in the mobile phase. Constant $C$ derived from the fact that mass transfer cannot be instantaneous, and three resistances to mass transfer coefficients should be considered: in the mobile phase, in the stationary phase and interfacial resistance, the latter linked to rate constant of the partitioning process. Furthermore, the velocity profile in a capillary column is normally parabolic and the flow is laminar; if not, " $A$ " tends to increase and so the height equivalent to a theoretical plate, i.e., a reduction in the overall performance occurs ${ }^{(40)}$. In the last decade or so, this equation was used several times in computational fluid dynamics simulations of liquid or gaseous chromatography ${ }^{(41-43)}$. Furthermore, sometimes the number of theoretical plates, not $H$, is determined, in such cases, simply by the division of the column length by the $H$.

During chromatographic column manufacturing and use, " $A$ " is usually minimized by the correct choice of spare parts, optimization of parameters, etc.; moreover, in capillary columns, it is commonly assumed as zero.

In many simulations, such as the ones derived in COMSOL (FEMLAB) $3.2^{\circledR}$, the equilibrium for the analyte between the mobile and stationary phase is assumed to be immediate. Therefore, peak broadening is normally correlated with overall diffusion processes and expressed as a function of a diffusion constant and the analyte velocity through the column (Eq. 2). 


$$
\mathrm{D}_{\text {eff }}=\frac{\mathrm{Hv}_{\mathrm{zi}}}{2}
$$

where; $D_{\text {eff }}=$ effective diffusion constant; $v_{z i}=$ migration velocity of the analyte zone through the column; $H=$ height equivalent of a theoretical plate.

However, such an approach considers an isotropic diffusion, which is not necessarily true in curved geometry, for instance due to dispersion, i.e. a high axial diffusion. In such cases, an artificial diffusion coefficient is admitted in simulations, in which coefficients are based on the Petrov-Galerkin model and/or any other equation added to the diffusion cons$\operatorname{tant}\left(D_{e f f}\right)$, and this work will consider both alternatives.

\section{Materials and Methods}

Two distinct microstructures were manufactured, as can be seen in Fig. 1. Both microstructures, planar and three-dimensional, show a $73 \mathrm{~cm}$ long, $100 \mu \mathrm{m}$ wide and $40 \mu \mathrm{m}$ deep channel. Planar channel design is a spiral similar to the one proposed previously ${ }^{(27)}$ but without the periodic constriction and the three-dimensional channel is similar to the one also introduced earlier ${ }^{(29)}$. These structures present surface and volume of $1.4 \mathrm{~cm}^{2}$ and $1.1 .10^{-3} \mathrm{~cm}^{3}$, respectively, i.e. surface/volume ratio of 1300 .

The structures were manufactured in poly (methyl methacrylate) - acrylic (Plastotal Ltda., Brazil), with conventional tools. Acrylic was used due to the optical transparency that allows photographic tests. Threedimensional channels were sealed using silicone glue and planar channels with a $5 \mu \mathrm{m}$ thick tape (YR-9767, $3 \mathrm{M}$, USA). The integrity of both structures was evaluated and corresponds to an overpressure up to $3 \mathrm{~atm}$, either

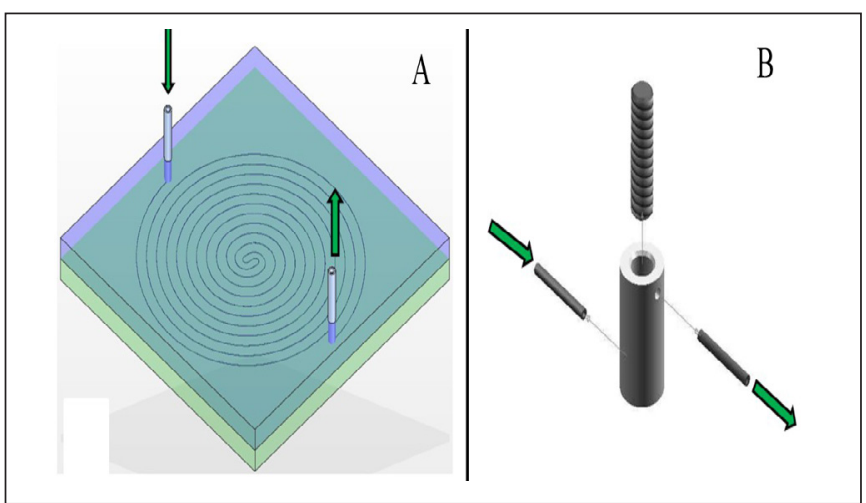

Figure 1. Manufactured microstructures with planar (A) and three-dimensional (B) microchannels. in liquid or gaseous flow. Roughness and channel profile were evaluated using secondary electron microscopy (SEM, NovaNanoSEM 400, FEI, USA). Furthermore, some of these microchannels were modified by plasma deposition of hexamethyldisilazane (HMDS) thin films ${ }^{(30)}$ that easily adsorb organic compounds.

The structures were tested in two different ways by using tracers and reactants in a wide range of polarity, respectively: tests and simulation used fluid flow rates up to 10 standard $\mathrm{mL} / \mathrm{min}$ for gaseous samples an up to $1 \mathrm{~mL} / \mathrm{min}$ for liquid ones. These ranges correspond to laminar flows (low Reynolds number, much less than 2,300 ) and the fluids used were nitrogen or water, in gas or liquid phase, respectively.

Tracers and filming (Sony, DSCW7 - P72, USA) were used in unmodified channels for determining liquid fluid behavior. The used tracers are $10 \%$ wt. methylene blue aqueous or glycerol solutions. Tests with reactants in a wide range of polarity aimed at the evaluation of retention and/or elution in the channels. The reactants, n-Hexane, 2-Propanol and water, were injected quickly $(<<1$ s) and in small quantities $(<<1 \mathrm{~mL})$. The tests used a homemade system composed by a heating module, microelectrodes and two quartz crystal microbalances (QCMs) as detectors for gas and liquid measurement ${ }^{(44)}$. All tests were performed at room temperature using QCM and a piezoelectric quartz crystal (PQC) covered with an adsorbent thin film of Hexamethyldisilazane (HMDS) deposited on the surface. The reactants are all P.A (Casa Americana SA, Brazil) but HMDS is industrial grade. Only distilled water was used in flow tests and solutions preparation. Optical microscopy used conventional equipment (Baush\&Lomb, model 311871).

Simulation was carried out regarding two different situations, gas and liquid fluids, in order to determine velocity profile and pressure changes. These parameters help to figure out the best conditions for retention/separation, i.e. mainly preconcentration and chromatographic uses. Incompressible Navier-Stokes 2D or 3D simulations, COMSOL (FEMLAB) 3.2 or COSMOS flow 5.0 programs and a QuadCore platform $(2.66 \mathrm{GHz}, 8 \mathrm{~GB}$ of RAM) were used. COSMOS flow program is more adequate to determine velocity field and pressure profile and also presents direct models to determine viscosity and density. COMSOL (FEMLAB) deals better with the interaction of two or more different fluids. Therefore, microchannels velocity profile was obtained by using 
COSMOS flow, but analyte concentration variation was simulated on COMSOL (FEMLAB) program. Due to the small dimensions, gravity effects were considered nonexistent.

\section{Results and Discussion}

As stated before, constructive aspects of chromatography columns play an important role in the van Deemter Equation and are quoted in constant $A$ in that equation. In order to minimize such an influence on these miniaturized structures, constructive factors were evaluated/manipulated as follows:

Profile and roughness: in these microchannels, the profile channel is approximately triangular, as can be seen in the SEM microscopy presented in Fig. 2, and roughness much less than $10 \mu \mathrm{m}$. This roughness does not present any structure regularly distributed, which might favor preconcentration by capillary effect ${ }^{(27)}$. Moreover, no meaningful difference was perceived between the two channels due to different machining process. Furthermore, HMDS thin film planarizes the surface during deposition ${ }^{(30)}$. Nonetheless, tests using propylene capillaries were also carried out to evaluate the relevance of non-uniformities on these surfaces, as explained later.

Sealing: the sealing process does not interfere with the channel inner surface; nevertheless, two sealed structures were disassembled and evaluated in optical and SEM microcopies and around the bonding area no evidences of sealing residues were found inside the channel.

Inlet system: exactly the same equipment was used, only the column was changed.

Detector: both inlet and detector system belong to the same equipment.

Injection: although injection was performed manually, only one operator carried out all the experiments. Injection reproducibility was checked by insertion in capillaries with several internal diameters (from $0.1 \mathrm{~mm}$ to $1 \mathrm{~mm}$ ) and analysis of peak profile. No significant differences were found.

Thus, for experimental purposes, it was assumed that there is no relevant difference in constant $A$ for these structures. Constant $C$ was addressed considering that immediate equilibrium and/or mass transfer can be approximately accomplished by just increasing the sample amount. This approach only implies that $H$ on van Deemter Equation will be quite low, i.e., the structures will present a low chromatographic performance, although their fluid behavior will be better understood. Therefore, in all experiments performed, the injected sample amount was $0.01 \mathrm{~mL}$, i.e., $1 \%$ of the whole channel volume. This injection also occur in a laminar flow and using a FIA (continuous flow injection system), which assures a linear velocity low enough to avoid mixing by secondary phenomena in regions positioned before the microchannel inlet

Planar spiral behavior

This structure shows a low Dean number (Equation 2), which indicates that pressure gradient and flow rate are not dependent on the curvature and the axial velocity profile is parabolic and unaltered from a straight tube ${ }^{(25)}$. Fig. 3 shows the resultant velocity and absolute pressure profiles on a planar spiral with air, glycerol and water as fluids, while Table 1 shows the highest velocity values. Whereas all conditions show linear pressure decay, velocity profiles show a cyclic variation, apparently correlated with the location regarding the structure center. This behavior is probably due to the great variation in velocity vectors in this center. It is worth noting that convergence in water flow simulation requires the assumption of a turbulent flow, probably due to the water physical properties being far from ideal gas data.

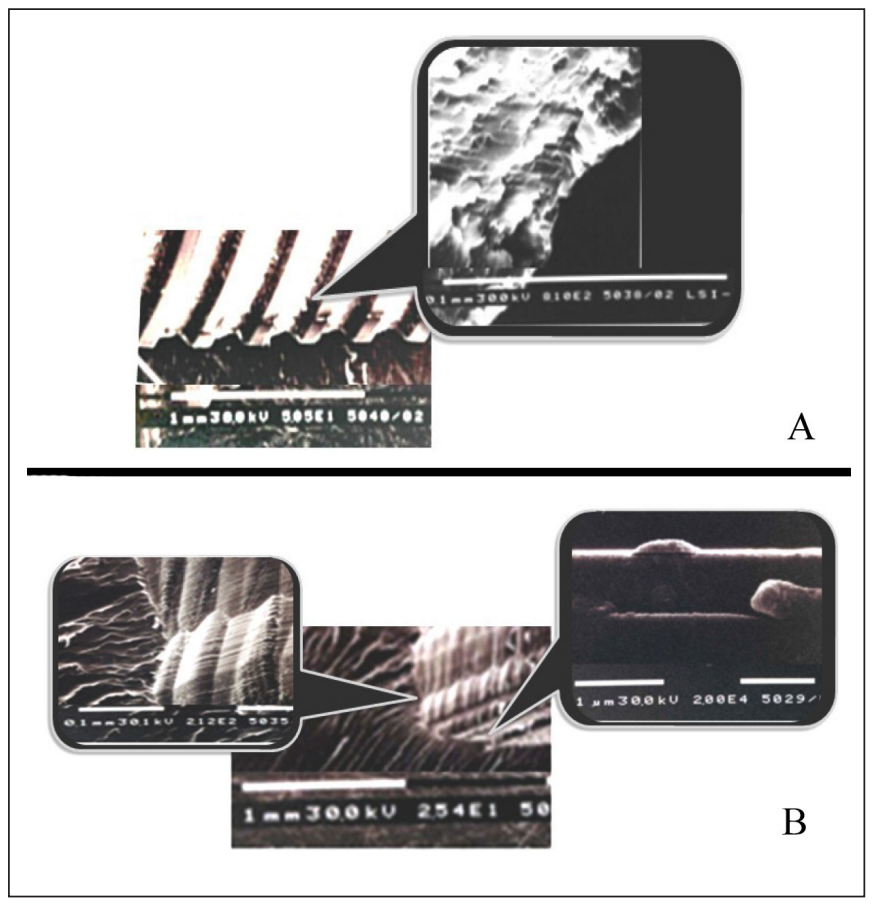

Figure 2. SEM microscopy of the microchannels: (A) profile of three-dimensional microchannel and roughness (detail);

(B) planar microchannel with roughness and planarization effect of HMDS film deposition (details) . 
Moreover, the oscillation in the resultant velocity is more evident in the liquid phase, probably due to the high axial velocity. Therefore, there are differences between simulation results and the analytical models used in curved geometry probably not due to the spiral itself, but to the design in the center that corresponds to two small $180^{\circ}$-bends or, in other words, as the simulated structure is a double spiral, tubes connection can create turbulences or variation in flow profile. Any attempt carried out by simulation to significantly decrease this velocity by changing the $180^{\circ}$ - bends fails.

These velocity profiles might favor separation of two different fluids, as can be seen in Fig. 4, which shows the concentration profile of $n$-hexane in nitrogen ( $50 \%$ vol.) or an aqueous saturated flow. In both figures, an increase in analyte concentration prevails in a small area of the microchannel length; however, a higher dispersion seems to occur in water, probably due to a mass transfer phenomenon.

In all fluids, the high axial velocity, shown in Table 1, might explain the flow dispersion observed in tracer experiments, as explained later. Furthermore, glycerol and water velocity values are compatible only if a small amount of glycerol sample is added to the channel; if the flow increases, the inlet pressure will raise quickly, reaching 20 atm to $1 \mathrm{~mL} / \mathrm{min}$, an unusually high range on MEMS devices. This result is easily understood considering it is difficult to move the more viscous fluid in the presence of capillary effect, with the system air/glycerin already simulated ${ }^{(45)}$.

The visualization of fluid behavior using tracers can be carried out in liquid phase using methylene blue solutions and Fig. 5 depicts frame sequences for injection of aqueous and glycerol solutions into the liquid flow (water). Whereas the flowing of an aqueous solution seems to be homogeneous, the viscous substances show a more erratic behavior, i.e., the flow presents some turbulence and "collisions" occur with the walls, probably due to the flow dispersion. Although particles can leave the structure without difficulty, it was also possible to observe a similar behavior. Moreover, the sample can be partially retained for a few seconds if a low throughput, such as $0.35 \mathrm{~mL} / \mathrm{min}$, is used.

Although visualization is not possible in the gas phase, the injection of a reactant into the flow can be detected and correlated with fluid behavior. The simulated results are in good agreement with the observation that planar spiral favors retention of volatile organic compounds (VOCs) in gaseous phase $\mathrm{e}^{(27)}$ or even in liquid if the surface is changed by deposition of an adsorbent film ${ }^{(26)}$.

Table 1. Highest velocities in the planar spiral microchannel using water, glycerol and air as fluids. Three-dimensional simulation with outlet pressure of $1 \mathrm{~atm}$.

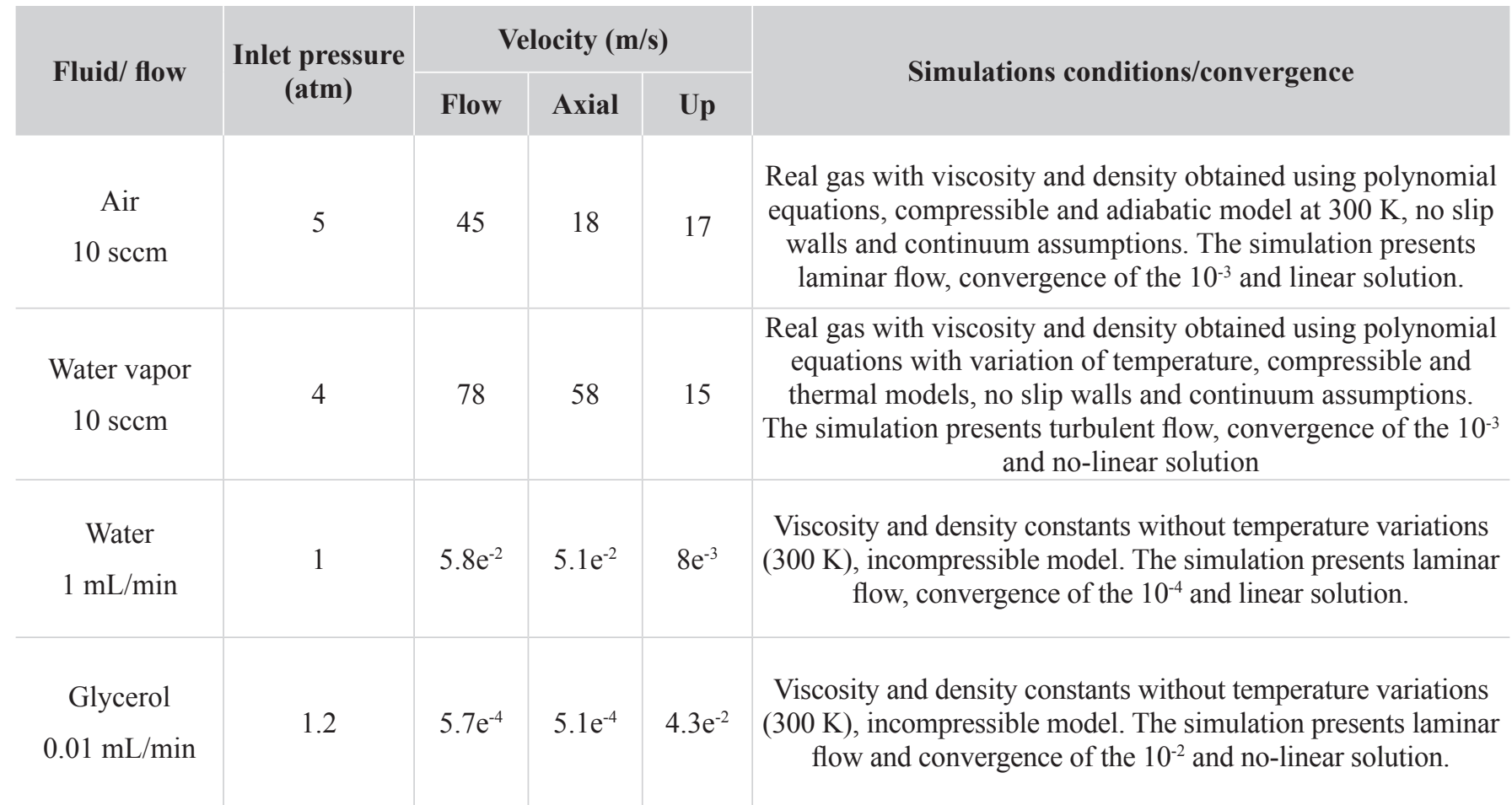

Flow - velocity responsible for fluid traveling inside the channel; Axial - velocity responsible for fluid dispersion inside the channel; Up - velocity responsible for chaotic behavior inside the channel, related to the friction factor. Respectively, $V x, V y$ and $V z$ in Fig. 3 


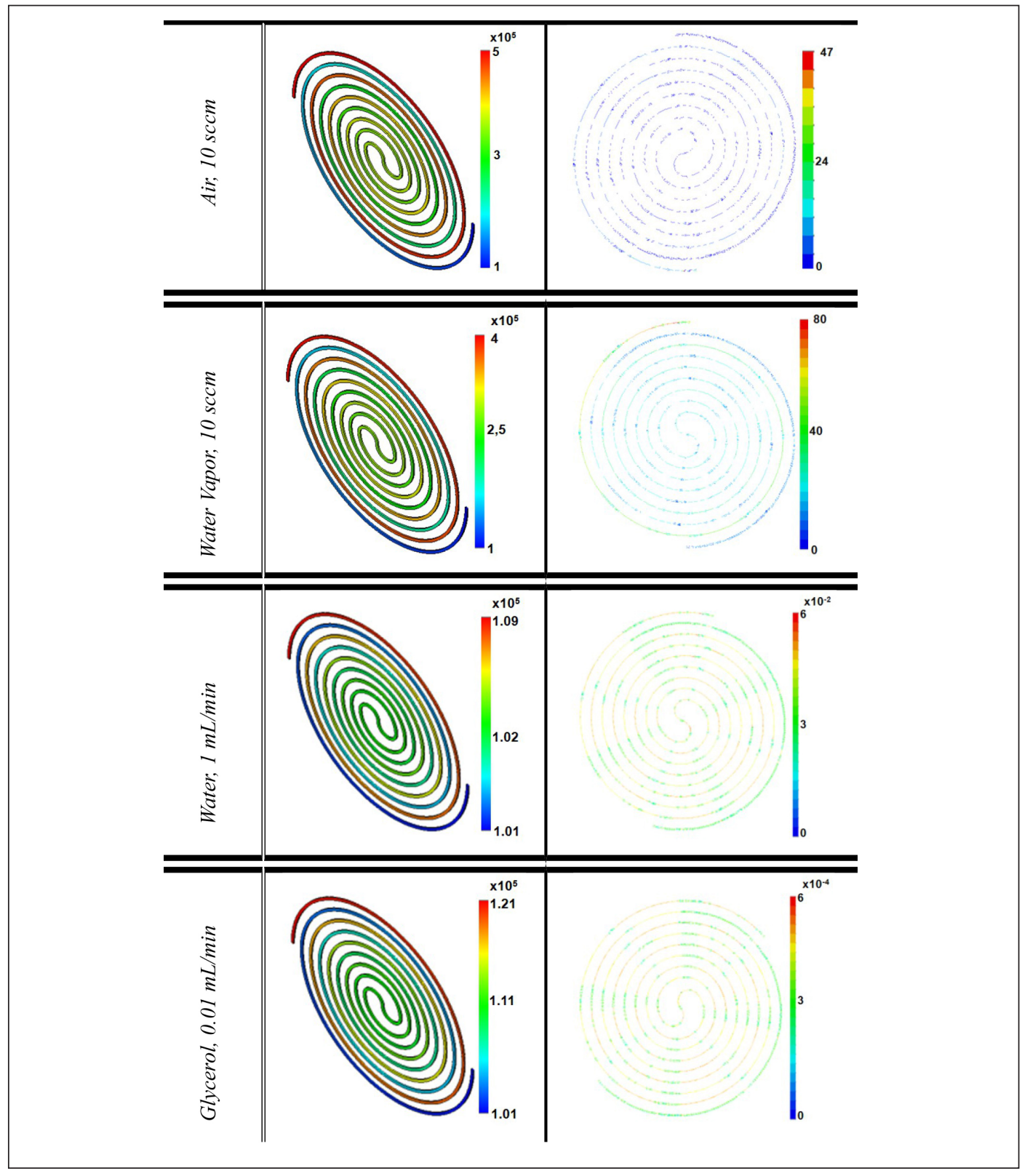

Figure 3. Resultant Velocity $(\mathrm{m} / \mathrm{s})$ and absolute pressure $(\mathrm{Pa})$ profiles on a planar spiral with air, glycerol and water as fluids using COSMOS Flow 5.0 program.

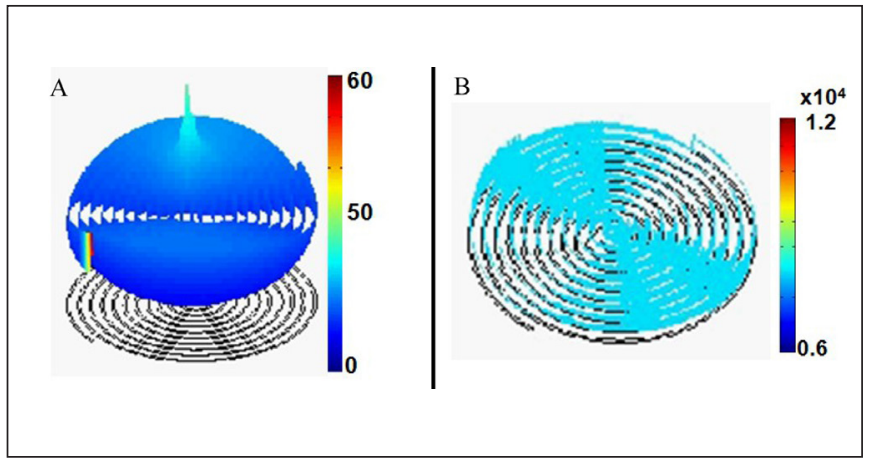

Figure 4. Concentration profile of $n$-hexane in $(\mathrm{A})$ nitrogen (50\%vol.) and (B) an aqueous saturated flow (a.u.) using COMSOL(FEMLAB) 3.2 program.
Therefore, the fluid dispersion allows VOCs molecules to reach the surface many times during their traveling through the channel; in such a condition, in a chromatographic column, retention time increases whereas the number of theoretical plate decreases due to eddy diffusion $^{(46)}$. Thus, some channels were covered with HMDS plasma deposited thin film (100 nm thick) and evaluated as a chromatographic column. Typical results can be seen in Table 2 for 2-propanol and n-hexane as reactants. Due to film presence, the number of theoretical plates and retention time can slightly increase, which indicates 
a minor interaction with film present in the surface, i.e., the reactant removal is probably driven mainly by flow behavior, not by adsorption phenomena.

\section{Three-dimensional channel}

Figure 6 shows resultant velocity and absolute pressure profiles in a three-dimensional spiral with air, glycerol and water as fluids and Table 3 shows the highest velocity values. For all conditions, pressure decay is linear and pressure difference is quite low, if compared to planar spiral. Moreover, flow dispersion due to axial velocity is low even with water vapor, a non-ideal gas, simulations do not require temperature changes and the flow is always laminar; therefore, this structure resembles either gas or liquid chromatographic column. Thus, retention time and the number of theoretical plates were

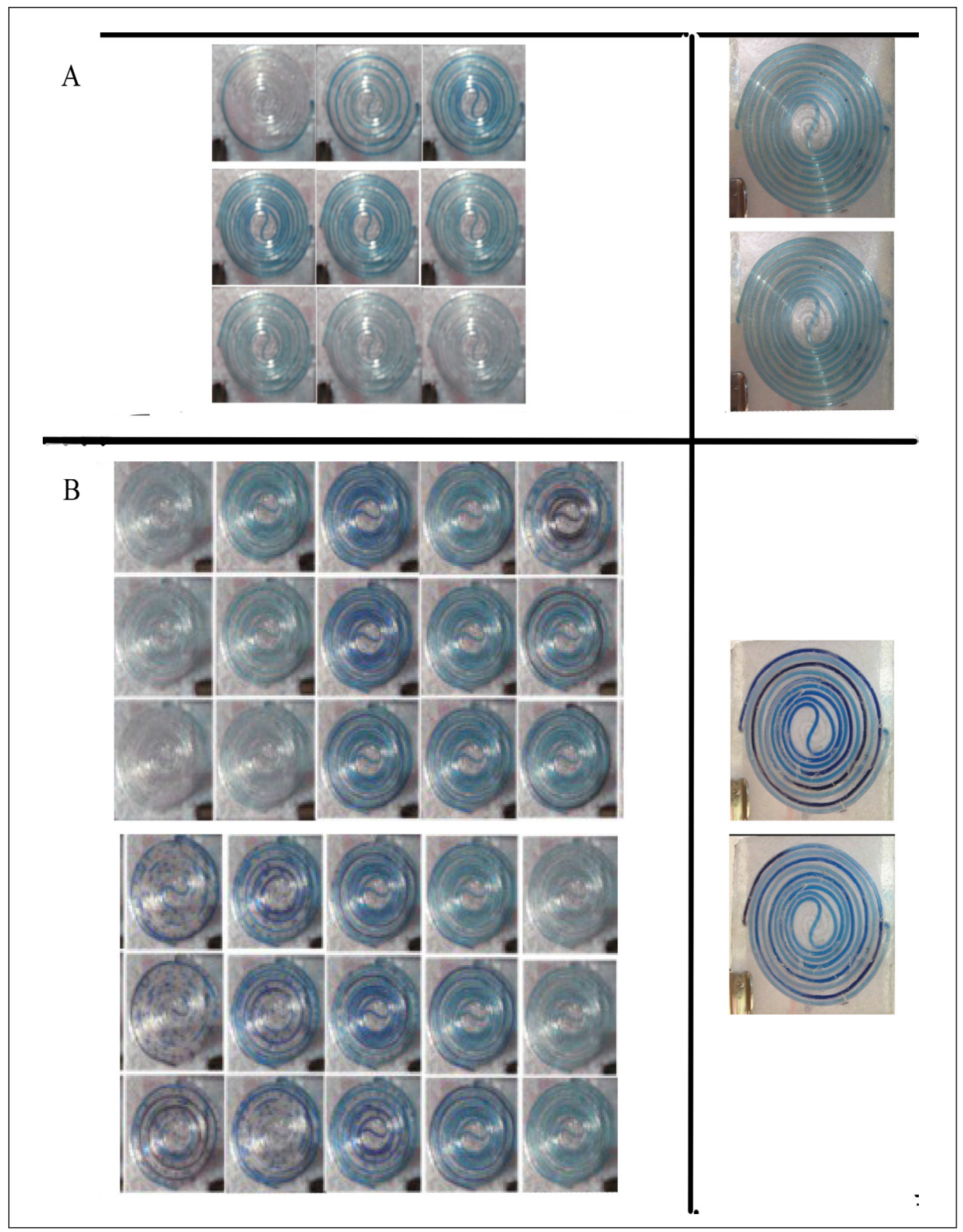

Figure 5. Frame sequence for tracer injection on water flow: methylene blue (A) aqueous or (B) glycerol solutions 
Table 2. The calculated number of theoretical plates and measured retention time for planar spiral (10 sccm, air)

\begin{tabular}{|c|c|c|c|c|}
\hline Reactant injected & $\begin{array}{c}\text { Retention time } \\
\text { (min) }\end{array}$ & $\begin{array}{c}\text { No. of theoretical } \\
\text { plates }\end{array}$ & $\begin{array}{c}\text { Height equivalent to a theoretical } \\
\text { plate (cm) }\end{array}$ & $\begin{array}{c}\text { HMDS thin film } \\
\text { present }\end{array}$ \\
\hline \multirow{2}{*}{ n-hexane } & 0.588 & 1.863 & 39 & $\mathrm{Y}$ \\
\hline \multirow{2}{*}{ 2-propanol } & 0.696 & 3.224 & 22 & $\mathrm{~N}$ \\
\hline & 1.070 & 6.093 & 12 & $\mathrm{Y}$ \\
\hline
\end{tabular}

measured, as explained previously, and they are presented in Table 4 for n-hexane and 2-propanol. It is possible to observe distinct behavior if the structure is covered by an adsorbent film or the reactant is changed, which point out that this structure behaves as a chromatographic column even with a high sample amount, which is in good agreement with simulation results.

Figure 7 shows glycerol solution (tracer) injected in the three-dimensional channels. The frames showing the flow (Fig. 7A) seem to be homogeneous all the time and optical microscopy in these microchannels allows observing a regular distribution of the dye solution inside the channel (Fig. 7B).
These conditions are also observed with aqueous solutions or if particles are allowed in the flow. Therefore, flow homogeneity is probably due to the low axial velocity and the structure resembles a chromatographic column.

Qualitative model

A qualitative modeling to fluid behavior can be obtained using COMSOL (FEMLAB) $3.2^{\circledR}$ and the chromatographic band profile. In this program, the following parameters can be changed in order to model analyte concentration inside

Table 3. Highest velocities in three-dimensional spiral microchannel using water, glycerol and air as fluids. Three-dimensional simulation with outlet pressure of $1 \mathrm{~atm}$ and $300 \mathrm{~K}$

\begin{tabular}{|c|c|c|c|c|c|}
\hline \multirow{2}{*}{ Fluid/ flow } & \multirow{2}{*}{$\begin{array}{l}\text { Inlet pressure } \\
\text { (atm) }\end{array}$} & \multicolumn{3}{|c|}{ Velocity (m/s) } & \multirow{2}{*}{ Simulations conditions/convergence } \\
\hline & & Flow & Axial & Up & \\
\hline $\begin{array}{c}\text { Air } \\
10 \mathrm{sccm}\end{array}$ & 1.1 & 3.3 & 3.4 & 0.4 & $\begin{array}{l}\text { Real gas with viscosity and density obtained using polynomial } \\
\text { equations, laminar flow, compressible and adiabatic model, no } \\
\text { slip walls and continuum assumptions. The simulation presents } \\
\text { convergence of the } 10^{-4} \text { and linear solution. }\end{array}$ \\
\hline $\begin{array}{l}\text { Water vapor } \\
10 \mathrm{sccm}\end{array}$ & 1.1 & 4.7 & 4.8 & 0.57 & $\begin{array}{l}\text { Real gas with viscosity and density obtained using polynomial } \\
\text { equations, laminar flow, compressible and adiabatic model, no } \\
\text { slip walls and continuum assumptions. The simulation presents } \\
\text { convergence of the } 10^{-4} \text { and no-linear solution. }\end{array}$ \\
\hline $\begin{array}{l}\text { Water } \\
1 \mathrm{~mL} / \mathrm{min}\end{array}$ & 1.1 & $6.7 \mathrm{e}^{-2}$ & $6.7 \mathrm{e}^{-2}$ & $9.1 \mathrm{e}^{-3}$ & $\begin{array}{l}\text { With viscosity and density constants without temperature } \\
\text { variations, laminar flow and incompressible model. The } \\
\text { simulation presents convergence of the } 10^{-4} \text { and linear solution. }\end{array}$ \\
\hline $\begin{array}{c}\text { Glycerol } \\
0.01 \mathrm{~mL} / \mathrm{min}\end{array}$ & 1.1 & $1.3 \mathrm{e}^{-2}$ & $1.3 \mathrm{e}^{-2}$ & $4.2 \mathrm{e}^{-3}$ & $\begin{array}{l}\text { Viscosity and density constants without temperature variations, } \\
\text { laminar flow and incompressible model K. The simulation } \\
\text { presents convergence of the } 10^{-3} \text { and non-linear solution. }\end{array}$ \\
\hline
\end{tabular}

Flow - velocity responsible for fluid traveling inside the channel; Axial - velocity responsible for fluid dispersion inside the channel; Up - velocity responsible for chaotic behavior inside the channel, related to the friction factor. Respectively, $V x, V y$ and $V z$ in Fig. 6 


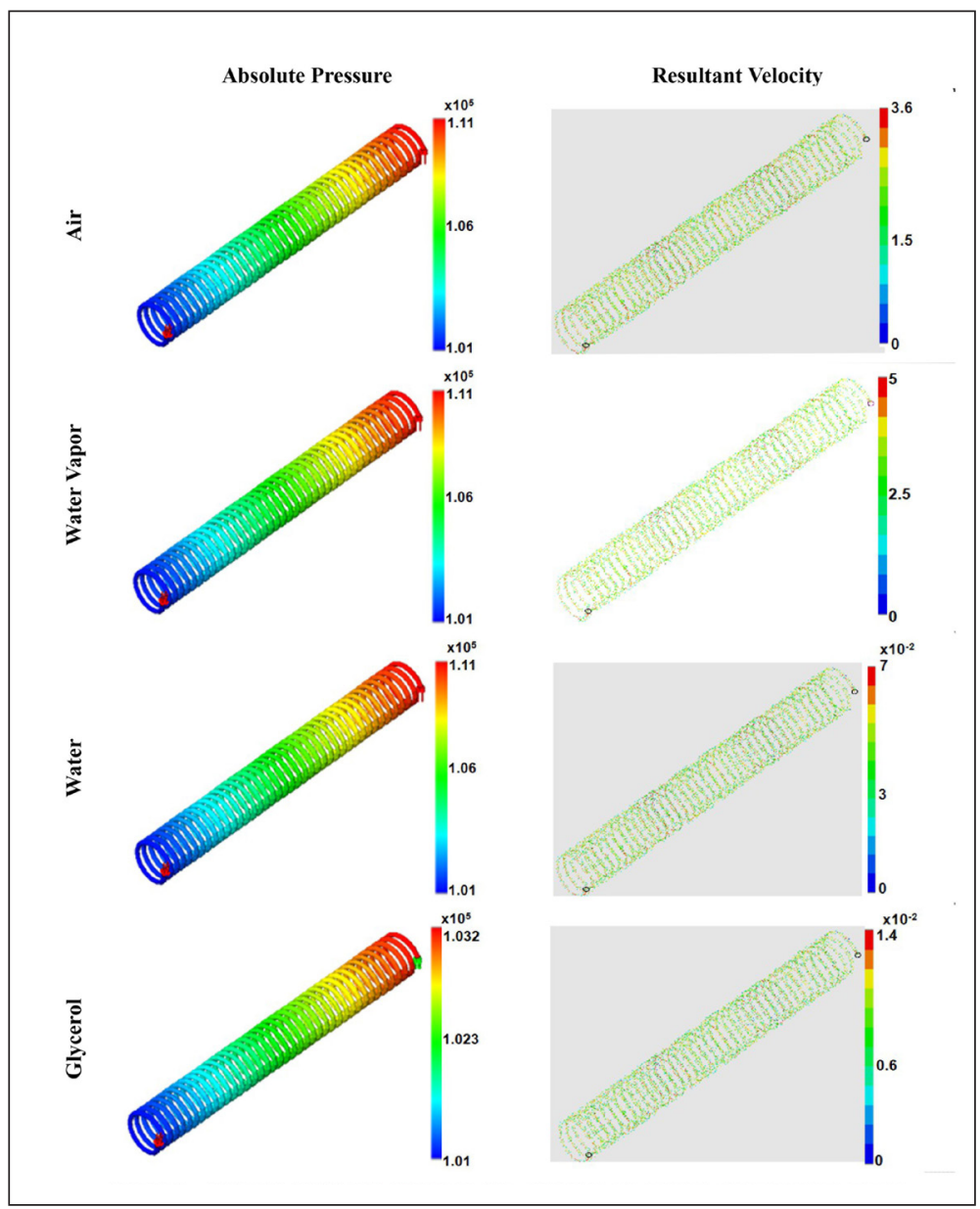

Figure 6. Velocity $(\mathrm{m} / \mathrm{s})$ and pressure $(\mathrm{Pa})$ profiles on a three-dimensional spiral with air, glycerol and water as fluids using COSMOS flow 5.0 program.

Table 4. The calculated number of theoretical plates and measured retention time for three-dimensional spiral (10 sccm air).

\begin{tabular}{|c|c|c|c|c|}
\hline Reactant injected & $\begin{array}{c}\text { Retention time } \\
\text { (min) }\end{array}$ & $\begin{array}{c}\text { No. of theoretical } \\
\text { plates }\end{array}$ & $\begin{array}{c}\text { Height equivalent to a } \\
\text { theoretical plate (cm) }\end{array}$ & $\begin{array}{c}\text { HMDS thin film } \\
\text { present }\end{array}$ \\
\hline \multirow{2}{*}{ n-hexane } & 0.053 & 5.587 & 13 & $\mathrm{Y}$ \\
\hline \multirow{2}{*}{ 2-propanol } & 1.570 & 0.849 & 86 & $\mathrm{~N}$ \\
\hline & 0.089 & 62.693 & 0.048 & $\mathrm{Y}$ \\
\hline
\end{tabular}

the chromatographic channel: a) column length $(73 \mathrm{~cm})$; b) column area (equals to surface channel); c) column porosity (equals 1 , since it is a capillary column); d) velocity of mobile phase flow (equals flow velocity in Tables 2 and 3); e) effective diffusion (a parameter to be tunneled, as explained in experimental); f) adsorption constant (assumed as $0.04 \mathrm{~m}$, a common value to moderate adsorbed VOCs compounds); g) concentration in the stationary phase (assumed to be $10^{-6} \mathrm{~mol} / \mathrm{m}^{2}$, an approximate value to HMDS thin film); g) analyte concentration (corresponds to the amount of

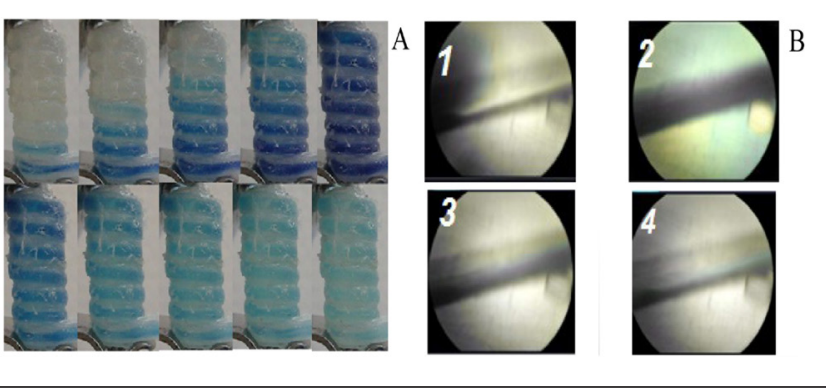

Figure 7. (A) Frames of glycerol solution injected in the three-dimensional channels and (B) details of microchannel photographed using an optical microscope. 
reactant injected and the respective inlet volume; in this case, approximate value of $\left.1 \mathrm{~mol} / \mathrm{m}^{3}\right)^{(26-29)}$. Diffusion coefficients $\left(D_{\text {eff }}\right)$ are usually in order to $10^{-8} \mathrm{~m}^{2} / \mathrm{s}$; however, in conical tubes dispersion is present and dispersion coefficients of $10^{-4} \mathrm{~m}^{2} / \mathrm{s}$ are possible ${ }^{(47,48)}$. Therefore, not only $10^{-8} \mathrm{~m}^{2} / \mathrm{s}$ but also $10^{-4} \mathrm{~m}^{2} / \mathrm{s}$ value was tested as effective diffusion coefficients.

Figure 8 shows the worst results for $n$-hexane aqueous solution, i.e., the injection corresponds to $0.1 \mathrm{~mL}$ of n-hexane at the highest water flow. In such conditions, whereas the spiral structure leads to a complete asymmetric band (Fig, 8A), the helical structure shows only a broadening in peak (Fig. 8B). Simulations using FEMLAB were also carried out in order to reproduce an asymmetric peak, which can be made by assuming a high diffusion constant $\left(10^{-4} \mathrm{~m}^{2} / \mathrm{s}\right)$ coupled with a dependence on time $\left[\mathrm{D}_{\text {eff }}=1 \mathrm{e}^{-4}\right.$ $+(\sin (0.05 * t) * \sin (0.05 * t))]$, i.e., if it is considered that the axial velocity plays an important role in diffusion coefficient, its cyclic behavior might increase the secondary flow, which probably leads to the asymmetric concentration profile inside the channel (Fig. 8C1). If a strong adsorption in stationary phase $\left(10^{-3} \mathrm{~mol} / \mathrm{m}^{2}\right)$ is also assumed, the peak no longer exists (Fig. 8C2), i.e., the system works as a preconcentrator.

On the other hand, to the helical if the diffusion is isotropic (D1) or if there is an increment in lateral diffusion of only 2 times (Fig. 8D2) or even if diffusion changes exponentially to $10^{-4} \mathrm{~m}^{2} / \mathrm{s}$ (Fig. 8D3), the symmetry is only slightly influenced. Therefore, this structure is useful as chromatographic column in a wide range of conditions.

\section{Conclusions}

The behavior of three-dimensional microchannels (helical structures) was qualitatively evaluated in comparison with planar ones (spiral structures). Although both configurations were already successfully used as chromatographic columns, there are certain advantages in using three-dimensional microchannels as chromatographic columns and planar ones in preconcentrator units.

The results obtained, using tracers and visualization or reactants injection and chromatographic measurements, are in good agreement with simulations and points out other uses for planar or three-dimensional microchannels.

\section{Acknowledgment}

FAPESP and CNPq for financial support.

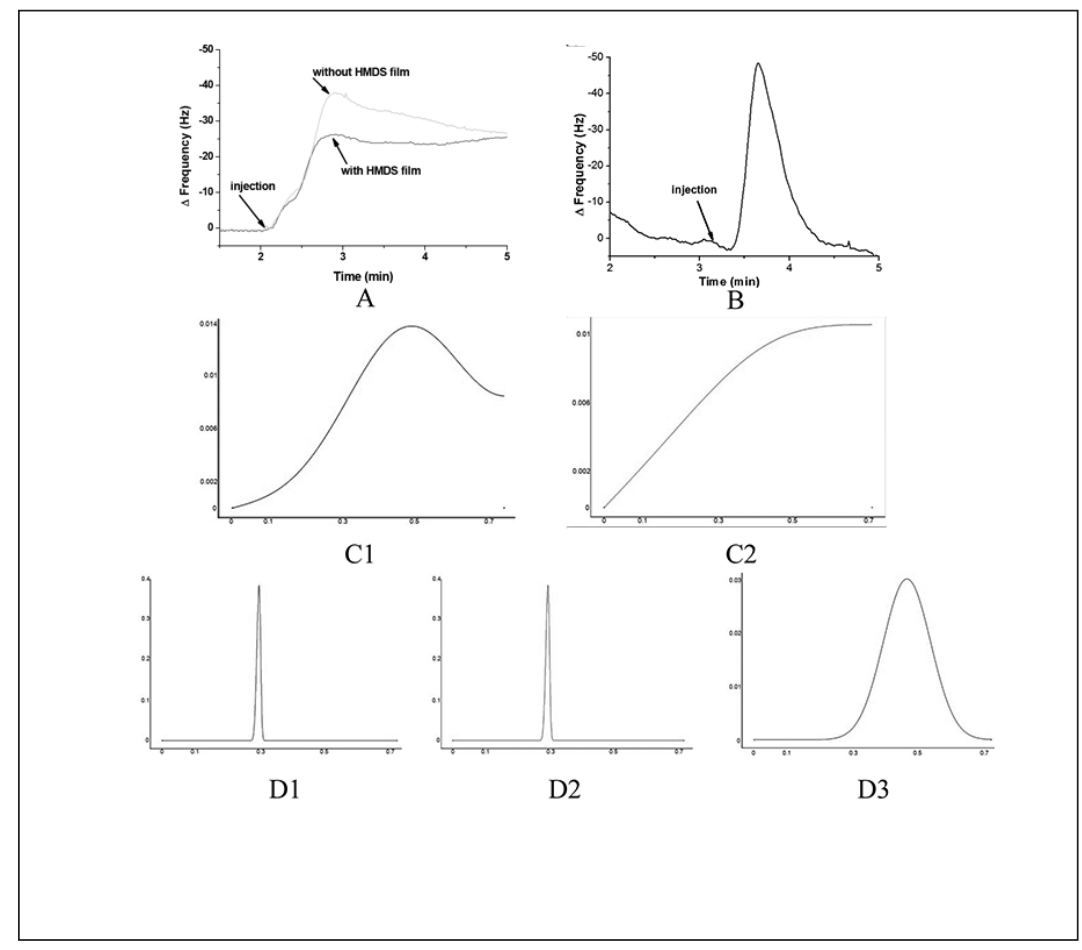

Figure 8. Peaks obtained at the worst conditions (n-hexane aqueous solution, injection of $0.1 \mathrm{~mL}$ at the highest water flow); (A) spiral structure; (B) helical structure. Simulations, analyte concentration in arbitrary units as a function of position (m) inside the channel: (C) spiral; (D1) helical with isotropic diffusion $\left(10^{-8} \mathrm{~m}^{2} / \mathrm{s}\right),(\mathrm{D} 2)$ increase in lateral diffusion $(2$ times) or (D3) increase in diffusion rate $\left(10^{-4} \mathrm{~m}^{2} / \mathrm{s}\right)$. 


\section{References}

1. Hessel, V.; Knobloch, C. Recent Patents on Chemical Engineering, (2008), 1, 1.

2. Editorial, The microchannel revolution, Focus on Catalysts (2), (2005), 1.

3. Mill, P.L.; Quiram, D.J.; Ryley, J.F.; Chemical Engineering Science, 62, (2007), 6992.

4. Grayson, R.; Shawgo A. C.; Johnson, R. S.; Flynn, A. M.; Li, N. T; Cima, Y; M. J; Langer. R. Proceedings Of The IEEE. 92 (1), (2004), 6.

5. Weigl, BH.; Bardell. RL.; Cabrera. CR.; Advanced Drug delivery reviews, 55, (2003), 349.

6. Daridon, A.; Fascio, V.; Lichtenberg, J.; Wütrich, R.; Langen, H.; Verpoorte, E.; Rooij, N. F.; Fresenius J Anal Chem, 371, (2001), 261.

7. Lobbecke, S.; Ferstl, W.; Panic, S.; Turcke, T.; Chem. Eng. Technol., 28, 4, (2005), 484.

8. Ohira, S.-I.; Toda, K.; Analytica Chimica Acta , 619, 2, (2008), 143.

9. Silva, G.; Leal, N.; Semiao, V.; International Journal of Heat and Fluid Flow, v. 29, Issue 4, (2008), 1211.

10. Silva, M. L. P.; Gameiro, J. G.; Revista Brasileira de Aplicações de Vácuo, v. 25, n. 3, (2006), 123.

11. Voiculescu, I.; Zaghloul, M.; Narasimhan, N.; Trends in Analytical Chemistry, v., Issue 4, (2008), 327.

12. Lewis, P. R.; Manginell, R. P.; Adkins, D. R.; Kottenstette, R. J.; Wheeler, D. R.; Sokolowski, S. S.; Trudell, D. E.; Byrnes, J. E.; Okandan, M.; Bauer, J. M.; Manley, R. G.; Frye-Mason, G. C.; IEEE SENSORS JOURNAL, v. 6, n. 3, (2006), 784.

13. Alfeeli, B. D.; Cho, M. Ashraf-Khorassani, L. T. Taylor, M. Agah; Sensors and Actuators B: Chemical Volume 133, Issue 1, (2008), 24.

14. Agah, M. Wise, K.D. Bradley, Electron Devices Meeting, IEEE International, (2005), 305.

15. Mello, A.; Lab Chip, (2002), 2, 48N.

16. WISE, K. D.; Sensors and Actuators A: Physical Volume 136, Issue 1, (2007), 39.

17. Gràcia, I.; Ivanov, P.; Blanco, F.; Sabaté, N.; Vilanova, X.; Correig, X.; Fonseca, L.; Figueras, E.; Santander, J.; Cane, C.; Sensors and Actuators B: Chemical, v. 132, Issue 1, (2008), 149.

18. Ali, S.; Ashraf-Khorassani, M.; Taylor, L. T.; Agah, M.; Sensors and Actuators B: Chemical, v. 141, Issue 1, 18, (2009), 309.
19. Zampolli, S.; Elmi, I.; Mancarella, F.; Betti, P.; Dalcanale, E.; Cardinali, G.C.; Severi, M.; Sensors and Actuators B: Chemical, v. 141, Issue 1, 18, (2009), 322.

20. Nakai, T; Nishiyama, S; Shuzo, M; Delaunay, J-J; Yamada, I.; J. Micromech. Microeng. 19, (2009), 1.

21. Hofmann, O.; Niedermann, P.; Manz, A.; Lab on a Chip, (2001), 1, 108.

22. Dittrich, P. S.; Manz, A.; Nature Reviews Drug Discovery 5, (2006), 210.

23. Nguyen, N.-T.; Wu, Z., J. Micromech. Microeng. 15, (2005), 1 .

24. Swickrath, M. J.; Burns, S.; Gary, D.; Wnek, E.; Sensors and Actuators B: Chemical Volume 140, Issue 2, 16, (2009), 656.

25. Vashisth, S.; Kumar, V., Nigam, K. D. P.; Ind. Eng. Chem. Res., 47, (2008), 3291.

26. Filho; A. P. N.; Carvalho, A. T.; Silva, M. L. P.; Demarquette, N. R.; Materials Research, Vol. 9, No. 1, (2006), 33.

27. Simões, E. W.; Souza, S. G., Silva; M. L. P.; Furlan, R.; Maldonado, H. E. P.; Sensors and Actuators B: Chemical, v. 115, Issue 1, (2006), 232.

28. Silva, L. M.; Lima, R. R.; Silva, M. L. P.; Madaleno, J. C.; Pereira, L.; Materials Science Forum, v. 514, p., (2006), 1250.

29. Lima, R. R.; Carvalho, R. A. M.; Nascimento Filho, A. P., Silva, M. L. P., Demarquette, N. R.. Silva, M, L, P., Sensors And Actuators B-Chemical, 108, (2005), 435.

30. Lima, R.r.; Carvalho, R.a.m.; Carvalho, A.t.; Simões, E.w.; Silva, M.1.p. Da, Sensors and Actuators B 137, (2009), 185.

31. Miwa, J.; Tan, W. H.; Yuji, S.; Kasagi, N.; Shikazono, N.; Furukawa, K.; Ushida, T.; The First International Conference on Bio-Nano-Information Fusion, Marina del Ray, CA, (2005).

32. Carvalho, A.T.; Lima, R.R.; da Silva, L.M.; Simões, E.W.; Silva, M.L.P.; Sensors and Actuators B 137, (2009), 393.

33. Hofmann, K.; Hala'sz, I.; J. Chromatogr., 173, (1979), 211.

34. Tijssen, R.; Anal. Chim. Acta, 114, (1980), 71.

35. Kumar, V.; Nigam, K. D. P.; Chem. Eng. Sci. 61, (2006), 5742.

36. BEDMAR, P. A.; Isotopos en Hidrologia. x ed. Madrid: Alhambra, (1972).

37. Mengeaud, V., Josserand, J.; Girault, H. H.; Anal. Chem., 74, (2002), 4279. 
38. Xia, H. M.; Wan, S. Y. M.; Shu, C.; Chew, Y. T.; Lab Chip, 5, (2005), 748.

39. Kang, T. G.; Kwon, T. H.; J. Micromech. Microeng. 14, (2004), 891.

40. Grob, R. L; Modern Practice Of Gas Chromatography, 4th ed., Eugene F. Barry, JOHN WILEY \& SONS, INC., (2004).

41. P. Gzil, G.; Baron, V.; Desmet, G.; Journal of Chromatography A, v. 991, Issue 2, 4 (2003), 169.

42. Vervoort, N.; P. Gzil, G.; Baron, V.; Desmet, G.; Journal of Chromatography v. 1030, Issues 1-2, 19, (2004), 177.
43. Billen, J.; P. Gzil, G., P. G., Baron, V.; Desmet, G.; Journal of Chromatography A, v. 1077, Issue 1, 3, (2005), 28.

44. Santos, L. C.; Beraldo, F. P.; Hernandez, L. F.; Carvalho, R. A. da Silva, M.; M. L. P.; Brazilian J. Vacum Society v. 25, Issue 2, (2006), 75.

45. Saghir, M. Z.; Chaalal, O.; Islam, M. R.; Journal of Petroleum Science and Engineering Volume 26, Issues 1-4, (2000), 253.

46. Smith, C.G.; Buzanowski, W.C.; Graham, J.D.; Iskandarani, Z.; CRC handbook of chromatography, CRC Press, Boca Raton, FL, (1982). 